\title{
Radiofrequency catheter ablation increases mean platelet volume
}

\section{SUMMARY}

OBJECTIVE: Radiofrequency ablation (RFA) may increase the risk of thromboembolic events. The objective of this study was to evaluate the effect of RFA on mean platelet volume (MPV), an indicator of platelet activity.

METHODS: A total of 95 patients undergoing RFA were included in the study. MPV was measured before and one month after the procedure. The control group was formed by 83 individuals of the same sex and age as those in the study group.

RESULTS: Beta-blockers, non-dihydropyridine calcium channel blockers, and acetylsalicylic acid use was higher in the ablation group compared with the control group. Other baseline clinical characteristics and baseline hemoglobin, white blood cell count, platelet count, and MPV values were similar between the ablation and control groups. In the ablation group, baseline and post-procedural hemoglobin, white blood cell counts were similar. However, postprocedural MPV values were higher, and platelet counts were lower compared with the preprocedural values.

CONCLUSION: Our results indicate that MPV values are higher after RFA compared with baseline values.

KEYWORDS: Mean platelet volume. Catheter Ablation. Thromboembolism.

\section{INTRODUCTION}

Platelet activation is involved in the pathogenesis of many thromboembolic diseases and has been shown to be associated with cardiovascular risk factors such as diabetes mellitus or hypertension and increased risk of cardiovascular events. ${ }^{1-6}$

Several methods, including platelet counts and size, aggregation and the levels of substances released from platelets have been described for determining platelet activation. However, most of them require complicated equipment, with high costs and time-consuming analysis methods, which prevents them from being used routinely in daily clinical practice. Mean platelet volume (MPV), has been introduced as an indicator of in vivo platelet activation. It is measured in the routine complete blood count test with a very simple method that can be performed at a low cost ${ }^{1}$. Increased MPV indicates larger platelets, which are more likely to be more reactive, increased

E-mail:dr.aksoy@hotmail.com 
aggregability, and decreased inhibition of aggregation. ${ }^{4,5}$ Increased MPV may also be associated with shortened bleeding time, increased thromboxane $\mathrm{A} 2$ and $\mathrm{B} 2$ concentrations, and higher expression of adhesion molecules. ${ }^{6}$ It has been shown that MPV is increased with cardiovascular risk factors, in cardiovascular, cerebrovascular or hematological diseases and in low-grade inflammatory diseases prone to arterial and venous thrombosis. On the other hand, high-grade inflammatory conditions such as rheumatic arthritis or Familial Mediterranean Fever attacks are associated with low values of MPV, which increase with anti-inflammatory treatment. ${ }^{1,3,7} \mathrm{Ra}-$ diofrequency ablation (RFA) is a very effective method for treating a wide variety of cardiac arrhythmias. However, this procedure has the potential to cause thromboembolism. ${ }^{8}$ To the best of our knowledge, no study has evaluated the effect of RFA on MPV. Therefore, the aim of this study was to assess the effect of RFA on MPV.

\section{METHODS}

\section{Population}

This study included 95 patients undergoing RFA and 83 apparently healthy individuals of the same age and sex as those in the study group. Patients with renal or hepatic failure, thrombocytopenia, thrombocytosis, active infection, malignancy, venous thrombosis, pulmonary embolism, congenital hemorrhagic disease, inflammatory disease, autoimmune disease, recent surgery, on oral contraceptives were excluded. Between May 2009 and May 2012, 105 patients undergoing RFA were screened, and 10 patients were excluded based on the exclusion criteria (diabetes mellitus, $\mathrm{n}=3$; heart failure, $\mathrm{n}=2$; hypertension, $\mathrm{n}=4$ and increased creatinine levels, $n=1$ ). Therefore, 95 patients were included in the RFA group (atrioventricular nodal reentrant tachycardia, $\mathrm{n}=44$; orthodromic reentrant tachycardia, $n=14$; antidromic reentrant tachycardia, $n=$ 20; idiopathic ventricular tachycardia, $\mathrm{n}=12$; atrial tachycardia, $n=4$; and atrial flutter, $n=1$ ). There were 21 left-sided procedures (antidromic reentrant tachycardia, $\mathrm{n}=8$ and orthodromic reentrant tachycardia, $n=13$ ) and the remaining 75 cases were right-sided procedures. The control group was chosen from the subjects who attended our cardiology clinics between 2009 and 2012 and were found to be healthy.

\section{Electrophysiological study and RF ablation procedures}

The procedures were performed in the fasting state without sedation. All the antiarrhythmics were discontinued for at least 5 half-lives before the procedure. Three sheaths were positioned into the femoral veins, and one sheath was positioned into the femoral artery that required arterial approach. Diagnostic 6 Fr catheters were positioned into the high right atrial, and its bundle locations (Medtronic, USA) and 6 Fr coronary sinus catheter were introduced into the coronary sinus (Bard, USA). An electrophysiological study with standard stimulation techniques was performed in each patient, and RFA was applied with the use of 4-mm tip 7 Fr deflectable catheter (Medtronic, USA). The pacing was performed with a stimulator at twice the diastolic threshold and with a pulse width of $2 \mathrm{~ms}$ (EP Tracer, Cardiotek, Netherlands). Intravenous heparin was used in the left-sided procedures with a target ACT level between 250-300 sec. Antiplatelet therapies with $100 \mathrm{mg}$ acetylsalicylic acid or clopidogrel in patients unable to receive acetylsalicylic acid were given for three months after the procedure. All the patients underwent transthoracic echocardiography before and one day after the procedure. The local Research Ethics Committee approved the study, and all the patients gave written informed consent.

\section{Hematologic measurements}

Hematologic measurements were performed before and one month after the procedure. Blood samples were drawn from the antecubital vein by careful venipuncture using a $21 \mathrm{G}$ sterile syringe without stasis in the morning. MPV was measured in a blood sample collected in dipotassium EDTAtubes. An automatic blood counter (Beckman Coulter LH 780) was used for the analyses. MPV was measured within 30 min after sampling to prevent EDTA-induced platelet swelling because it has been shown that platelets exhibit time-dependent swelling when blood samples are anticoagulated with EDTA and the measurement is not performed within 1 hour of sampling. ${ }^{9}$

Authors have participated sufficiently in the work to take public responsibility for appropriate portions of the content. The procedures were in accordance with the ethical standards of the institution's committee on human experimentation and the Helsinki Declaration of 1975, revised in 1983. 


\section{Statistical analysis}

Continuous variables were expressed as mean \pm SD, and categorical variables were expressed as frequency (\%). The changes in the laboratory findings before and after RFA were compared using a paired Student t-test. Continuous variables were compared by independent Student t-test. Categorical variables were compared with the chi-square test. It was assumed that baseline MVP values would be as a mean of $6.0 \mathrm{fl}$ and would increase to $9.0 \mathrm{fl}$ after the procedure. With this assumption, $97 \mathrm{RFA}$ patients were required to detect a significance with an alpha level of 0.05, and a power of 0.80. A two-sided p-value < 0.05 was considered significant. SPSS 11.0 version (Chicago, IL, USA) was used for analysis.

\section{RESULTS}

\section{Patients}

The rates of the baseline use of beta-blockers, non-dihydropyridine calcium channel blockers, and acetylsalicylic acid were higher in the ablation group compared with the control group (All $p$ values $<0.05)$. Other baseline clinical characteristics were similar between the ablation and control groups (All $p$ values $>0.05$; Table 1 ).

\section{Laboratory parameters: Ablation group vs. control group}

Baseline hemoglobin, white blood cell count, platelet count, and MPV values were similar between the ablation and control groups (All $p$ values $>0.05$ ). In the ablation group, pre-procedural and post-procedural hemoglobin and white blood cell count values were similar (Both $p$ values > 0.05). However, post-procedural MPV values were significantly higher, and platelet counts were lower compared with pre-procedural values (Both $\mathrm{p}<0.05$ values; Table 2 ). No thromboembolic events occurred in any group.
Laboratory parameters: Right-sided vs. leftsided ablation groups

Pre-procedural and post-procedural hemoglobin and white blood cell count values were similar in both right-sided and left-sided ablation groups (All $\mathrm{p}$ values $>0.05)$. However, post-procedural MPV values were significantly higher, and platelet counts were

TABLE 1. BASELINE CHARACTERISTICS

\begin{tabular}{|c|c|c|c|}
\hline Variables & $\begin{array}{l}\text { Ablation } \\
\text { group } \\
(n=95)\end{array}$ & $\begin{array}{l}\text { Control } \\
\text { group } \\
(n=83)\end{array}$ & $P$ value \\
\hline Age (years) & $47 \pm 16$ & $48 \pm 8$ & 0.54 \\
\hline Male gender $n, \%$ & $46(48.4)$ & $36(43.4)$ & 0.42 \\
\hline $\begin{array}{l}\text { Body mass index (kg/ } \\
\mathrm{m} 2)\end{array}$ & $27 \pm 3.8$ & $26 \pm 4$ & 0.42 \\
\hline Ejection fraction (\%) & $63 \pm 8$ & $63 \pm 2$ & 0.92 \\
\hline Heart rate (beats/min) & $79 \pm 20$ & $77 \pm 8$ & 0.34 \\
\hline $\begin{array}{l}\text { Systolic blood pressure } \\
(\mathrm{mmhg})\end{array}$ & $129 \pm 10$ & $132 \pm 6$ & 0.15 \\
\hline $\begin{array}{l}\text { Diastolic blood pressure } \\
\text { (mmhg) }\end{array}$ & $81 \pm 6$ & $79 \pm 3$ & 0.19 \\
\hline Glucose (mg/dl) & $102 \pm 24$ & $97 \pm 10$ & 0.12 \\
\hline Creatinine (mg/dl) & $0.9 \pm 0.19$ & $0.86 \pm 0.2$ & 0.07 \\
\hline LDL cholesterol (mg/dl) & $103 \pm 30$ & $105 \pm 28$ & 0.72 \\
\hline HDL cholesterol (mg/dl) & $47 \pm 13$ & $47 \pm 11$ & 0.90 \\
\hline Smoking $n, \%$ & $13(13.7)$ & $12(14.5)$ & 1 \\
\hline \multicolumn{4}{|l|}{$\begin{array}{l}\text { Pre-procedural treat- } \\
\text { ment }\end{array}$} \\
\hline Amiodarone $\mathrm{n}, \%$ & $6(6.3)$ & - & - \\
\hline Propafenone $n, \%$ & $3(3.2)$ & - & - \\
\hline Beta-blockers n, \% & $25(26.3)$ & $4(4.8)$ & $<0.0001$ \\
\hline $\begin{array}{l}\text { Non-dihidropiridine } \\
\text { calcium channel blocker } \\
\text { n, \% }\end{array}$ & $14(14.7)$ & $4(4.8)$ & 0.04 \\
\hline Acetylsalicylic acid n, \% & $43(45.3)$ & $12(14.5)$ & $<0.0001$ \\
\hline Clopidogrel n, \% & $2(2.1)$ & - & - \\
\hline Statin $n, \%$ & $8(8.4)$ & - & - \\
\hline ACEI/ARB n, \% & $13(13.7)$ & $6(7.2)$ & 0.6 \\
\hline
\end{tabular}

Abbreviations: $\mathrm{LDL}=$ low density cholesterol; $\mathrm{HDL}=$ high density cholesterol; $\mathrm{ACEI}=$ angiotensin-converting enzyme inhibitor; $A R B,=$ angiotensin receptor antagonist. Data were given as mean \pm SD or $n(\%)$.

TABLE 2. COMPARISON OF HEMOGRAM PARAMETERS BETWEEN THE ABLATION AND CONTROL GROUPS.

\begin{tabular}{l|l|l|l|l|l} 
Laboratory findings & \multicolumn{2}{l|}{$\begin{array}{l}\text { Ablation group } \\
(\mathrm{n}=95)\end{array}$} & $\begin{array}{l}\text { Control group } \\
(\mathrm{N}=83)\end{array}$ & P values \\
\hline & Pre-RFA & Post-RFA & & Pre-RFA vs. Control & Pre-RFA vs. Post-RFA \\
\hline White blood cell counts & $8280 \pm 2298$ & $7922 \pm 2110$ & $7933 \pm 2148$ & 0.31 & 0.2 \\
\hline Hemoglobin $(\mathrm{g} / \mathrm{dl})$ & $14 \pm 1.8$ & $14 \pm 1.9$ & $14 \pm 1.4$ & 0.25 & 0.9 \\
\hline Platelet count $\left(\mathrm{x} 10^{3}\right)$ & $305 \pm 82$ & $262 \pm 67$ & $288 \pm 67$ & 0.15 & $<0.0001$ \\
\hline MPV (fl) & $7.98 \pm 0.75$ & $8.88 \pm 1.06$ & $7.87 \pm 0.81$ & 0.35 & $<0.0001$ \\
\hline
\end{tabular}

Abbreviations: RFA, radiofrequency ablation; MPV, mean platelet volume. Data presented as mean \pm SD 
lower compared with the pre-procedural values in both right-sided and left-sided ablation groups $(\mathrm{p}<$ 0.05; Table 3).

\section{Relationship between MPV and ablation parameters}

There was no correlation between MPV and temperature $(r=-0.04, p=0.69)$, energy $(r=-08, p=0.46)$, or ablation application duration $(r=0.19, p=0.1)$.

\section{DISCUSSION}

The main finding of the present study is that MPV, an indicator of platelet activation, is higher after RFA when compared with the baseline. This was found after both the right-sided and leftsided ablation procedures. In the present study, no thromboembolic events occurred; however, we speculate that increased MPV might indicate increased platelet activity, which has been shown to be associated with thromboembolic events.

In the literature, it has been indicated that RFA may be associated with thromboembolism. Zhou et al. $^{8}$ have reported in their review that the overall incidence of thromboembolic complications of RFA is $0.6 \%$ and that it is increased to $1.8 \%$ to $2.0 \%$ in left heart procedures and to $2.8 \%$ when the procedure is performed for ventricular tachycardia. Haman et al. ${ }^{10}$ have analyzed data from 400 patients who underwent supraventricular tachycardia ablations and have found thromboembolic events at a rate of 1.75\%. Thakur et al. ${ }^{11}$ and Epstein et al. ${ }^{12}$ have also reported the incidence of thromboembolic events at a rate of $\sim 2 \%$. In a dog model, Khairy et al. ${ }^{13}$ showed that radiofrequency energy caused a higher incidence of thrombus formation and larger thrombus volumes than cryoablation. In 232 patients undergoing atrial fibrillation ablation, periprocedural symptomatic cerebrovascular events occurred at a rate of $0.4 \%$, and diffusion magnetic resonance imaging showed embolic events in $14 \%$ of the patients. ${ }^{14}$ In a large study, transthoracic echocardiography showed $\sim 0.1 \%$ of thrombotic complications. ${ }^{15}$

Thromboembolism most commonly occurs after left-sided RFA procedures (particularly when performed for the treatment of atrial fibrillation). In the present study, no atrial fibrillation ablation procedures were included. However, our results indicate that MPV increased after both the left-sided and right-sided ablation procedures, probably indicating that platelet activation is increased after both procedures. Hyperthermia induced by RFA energy may cause endothelial injury, protein denaturation, tissue necrosis, platelet adhesion and activation, and thus, thrombus formation..$^{8,10,13}$ In the literature, neurological ${ }^{11,12,16-18}$, pulmonary ${ }^{18,19}$, and arterial $^{18-20}$ thromboembolic events have been reported after this procedure. Radiofrequency ablation probably causes thromboembolism in patients who have a prothrombotic status, such as factor V Leiden mutation, protein $\mathrm{C}$ and $\mathrm{S}$ deficiencies, among others. However, we have not searched for those conditions in the present study.

No correlations were found between thromboembolic complications and duration of the procedure and number of the RF applications in a previous study. ${ }^{21}$ Similarly, although we did not detect any thromboembolic events, we did not find any correlation between RF parameters and MPV. In the daily clinical practice, heparin is used in left-sided RFA procedures, and acetylsalicylic acid is given for at least one month after all the RFA procedures.

It has been shown that D-dimer levels are lower with the combination of acetylsalicylic acid and ticlopidine after RFA. ${ }^{22}$ Also, catheter coagulum was found to be lower with temperature-controlled procedures compared with power-controlled procedures. ${ }^{23}$ We used heparin in the left-sided procedures

TABLE 3. COMPARISON OF HEMOGRAM PARAMETERS BETWEEN THE RIGHTSIDED AND LEFT-SIDED- ABLATION GROUPS.

\begin{tabular}{l|l|l|l|l|l|l} 
Laboratory findings & \multicolumn{2}{|l|}{$\begin{array}{l}\text { Right-sided ablation group } \\
(n=74)\end{array}$} & P-values & \multicolumn{2}{l}{$\begin{array}{l}\text { Left-sided ablation } \\
\text { group }(n=21)\end{array}$} \\
\hline & Pre-RFA & Post-RFA & & Pre-RFA & Post-RFA \\
\hline White blood cell counts & $8169 \pm 2141$ & $7886 \pm 1976$ & 0.7 & $8600 \pm 2905$ & $7994 \pm 2583$ & 0.25 \\
\hline Hemoglobin $(\mathrm{g} / \mathrm{dl})$ & $13 \pm 1.8$ & $13 \pm 1.9$ & 0.63 & $14 \pm 1.7$ & $14 \pm 2$ & 0.77 \\
\hline Platelet count $(\times 103)$ & $298 \pm 81$ & $261 \pm 68$ & $<0.0001$ & $332 \pm 86$ & $267 \pm 69$ & 0.004 \\
\hline MPV (fl) & $8.05 \pm 0.79$ & $8.98 \pm 1.04$ & $<0.0001$ & $7.76 \pm 0.61$ & $8.75 \pm 1.0$ & 0.002 \\
\hline
\end{tabular}

Abbreviations: RFA, radiofrequency ablation; MPV, mean platelet volume. Data presented as mean \pm SD. 
and acetylsalicylic acid at $100 \mathrm{mg} / \mathrm{d}$ for three months after all the procedures. On the other hand, it has also been reported that the use of heparin and temperature control do not completely prevent thromboembolic events. ${ }^{8,13}$ In addition, recent evidence shows that acetylsalicylic acid does not affect MPV. ${ }^{7}$

Our results may indicate that anticoagulant or more aggressive antiplatelet therapy may be required during RFA since MPV, an indicator of platelet activity, is increased after this procedure.

\section{Limitations}

The central problem was that we did not investigate the risk factors for thrombosis, such as factor $\mathrm{V}$ Leiden mutation, and protein $\mathrm{C}$ and $\mathrm{S}$ deficiencies. $\mathrm{Al}$ though the present study indicates increased MPV values after RFA, no thromboembolic events have been detected. This might be due to the small sample size of the study. MPV alone may not correctly reflect platelet functions. The use of other assessment methods for platelet function would be more reliable; however, they are time- consuming, costly, and require complex equipment. In addition, there are many studies in the literature that indicate the reliability of MPV; therefore, we used just MPV. No screening methods were used to detect thromboembolism, and the patients were just followed clinically. We did not include patients with diabetes mellitus, hypertension, heart failure, left ventricular systolic dysfunction, acute coronary syndrome, and moderate to severe heart valve disease. The duration of the recruitment was too long (Between 2009 and 2012). The expanded exclusion criteria and long duration of the study might represent a selection bias and influence the validity of the results. We did not measure inflammatory markers. Finally, control-group subjects were not tested for MPV at the post-ablation period.

\section{CONCLUSIONS}

Our results indicate that MPV is increased after RFA compared with the baseline. This increase occurred after both right-sided and left-sided ablation procedures. Larger studies are required to show the reliability of MPV as an indicator of increased platelet activity after RFA.

\section{RESUMO}

OBJETIVOS: A ablação por radiofrequência (ARF) pode aumentar o risco de eventos tromboembólicos. O objetivo foi avaliar o efeito da ARF no volume plaquetário médio (VPM), um indicador de atividade plaquetária.

MÉTODO: No total de 95 pacientes submetidos à ARF, o VPM foi medido antes e um mês após o procedimento. Oitenta e três pessoas do mesmo sexo e faixa etária constituíram o grupo controle.

RESULTADOS: Betabloqueadores, bloqueadores dos canais de cálcio não diidropiridínicos e uso de ácido acetilsalicílico foram maiores no grupo ablação quando comparados ao grupo controle. Outras características clínicas basais e hemoglobina basal, contagem de leucócitos, contagem de plaquetas e valores de VPM foram semelhantes entre os grupos de ablação e controle. No grupo de ablação, linha de base e hemoglobina pós-procedimento, as contagens de glóbulos brancos foram semelhantes. No entanto, os valores de VPM pós-procedimento foram maiores e as contagens de plaquetas foram menores em comparação com os valores pré-procedimento.

CONCLUSÕES: Nossos resultados indicam que os valores de VPM são maiores após a ARF em comparação com os valores basais. PALAVRAS-CHAVE: Volume plaquetário médio. Ablação por cateter. Tromboembolia.

\section{REFERENCES}

1. Yuri Gasparyan AY, Ayvazyan L, Mikhailidis DP, Kitas GD. Mean platelet volume: a link between thrombosis and inflammation? Current Pharm Des. 2011;17(1):47-58

2. Batista TR, Figueiredo RC, Rios DRA. Platelets volume indexes and cardiovascular risk factors. Rev Assoc Med Bras. 2018;64(6):554-9.

3. Gasparyan AY, Sandoo A, Stavropoulos-Kalinoglou A, Kitas GD. Mean platelet volume in patients with rheumatoid arthritis: the effect of anti-TNF- $\alpha$ therapy. Rheumatol Int. 2010;30(8):1125-9.

4. Jakubowski JA, Adler B, Thompson CB, Valeri CR, Deykin D. Influence of platelet volume on the ability of prostacyclin to inhibit platelet aggregation and the release reaction. / Lab Clin Med. 1985;105(2):271-6.

5. Karpatkin S, Khan Q, Freedman M. Heterogeneity of platelet function. Correlation with platelet volume. Am J Med. 1978;64(4):542-6.
6. Kamath S, Blann AD, Lip GY. Platelet activation: assessment and quantification. Eur Heart J. 2001;22(17):1561-71.

7. Xu RL, Zheng ZJ, Ma YJ, Hu YP, Zhuang SH. Platelet volume indices have low diagnostic efficiency for predicting bone marrow failure in thrombocytopenic patients. Exp Ther Med. 2013;5(1):209-14.

8. Zhou L, Keane D, Reed G, Ruskin I. Thromboembolic complications of cardiac radiofrequency catheter ablation: a review of the reported incidence, pathogenesis and current research directions. J Cardiovasc Electrophysiol. 1999;10(4):611-20.

9. Lancé MD, van Oerle R, Henskens YM, Marcus MA. Do we need time adjusted mean platelet volume measurements? Lab Hematol. 2010;16(3):28-31.

10. Haman L, Parizek P, Maly R, Duda J, Maly J. Analysis of thrombotic 
complications after catheter ablation. Acta Medica (Hradec Kralove) 2006;49(1):47-50

11. Thakur RK, Klein G], Yee R, Zardini M. Embolic complications after radiofrequency catheter ablation. Am J Cardiol. 1994;74(3):278-9.

12. Epstein MR, Knapp LD, Martindill M, Lulu IA, Triedman IK, Calkins H, et al. Embolic complications associated with radiofrequency catheter ablation. Atakr Investigator Group. Am J Cardiol. 1996;77(8):655-8.

13. Khairy P, Chauvet P, Lehmann J, Lambert J, Macle L, Tanguay JF, et al. Lower incidence of thrombus formation with cryoenergy versus radiofrequency catheter ablation. Circulation. 2003;107(15):2045-50.

14. Gaita F, Caponi D, Pianelli M, Scaglione M, Toso E, Cesarani F, et al. Radiofrequency catheter ablation of atrial fibrillation: a cause of silent thromboembolism? Magnetic resonance imaging assessment of cerebral thromboembolism in patients undergoing ablation of atrial fibrillation. Circulation. 2010;122(17):1667-73.

15. Calkins H, Yong P, Miller JM, Olshansky B, Carlson M, Saul JP, et al. Catheter ablation of accessory pathways, atrioventricular nodal reentrant tachycardia, and the atrioventricular junction: final results of a prospective, multicenter clinical trial. The Atakr Multicenter Investigators Group. Circulation. 1999;99(2):262-70

16. Cannon BC, Kertesz NJ, Friedman RA, Fenrich AL. Use of tissue plasminogen activator in a stroke after radiofrequency ablation of a left-sided accessory pathway. J Cardiovasc Electrophysiol. 2001;12(6):723-5.

17. Shih-Ann C, Chern-En C, Ching-Tai T, Chen-Chuen C, Chuen-Wang C, Shih-Huang $L$, et al. Complications of diagnostic electrophysiologic studies and radiofrequency catheter ablation in patients with tachyarrhythmias: an eight-year survey of 3,966 consecutive procedures in a tertiary referra center. Am J Cardiol. 1996;77(1):41-6.

18. Hindricks G. The Multicentre European Radiofrequency Survey (MERFS) investigators of the Working Group on Arrhythmias of the European Society of Cardiology. The Multicentre European Radiofrequency Survey (MERFS) complications of radiofrequency catheter ablation of arrhythmias. Eur Heart J. 1993;14(12):1644-53

19. Hockstad E, Gornick CC. Mildly symptomatic pulmonary emboli associated with electrophysiologic procedures. Indications for anticoagulant use. Chest. 1994;106(6):1908-11.

20. Hope El, Haigney MC, Calkins H, Resar IR. Left main coronary thrombosis after radiofrequency ablation: successful treatment with percutaneous transluminal angioplasty. Am Heart J. 1995;129(6):1217-9.

21. Farah A, Khan F, Machado C. Thrombus formation at the site of radiofrequency catheter ablation. Pacing Clin Electrophysiol. 2000;23(4 Pt 1):538-40.

22. Manolis AS, Vassilikos V, Maounis TN, Psarros L, Melita-Manolis H, Papatheou D, et al. Pretreatment with aspirin and ticlopidine confers lower thrombogenic potential of radiofrequency catheter ablation. Am Cardiol.1997;79(4):494-7.

23. Calkins H, Prystowsky E, Carlson M, Klein LS, Saul IP, Gillette P. Temperature monitoring during radiofrequency catheter ablation procedures using closed loop control. Atakr Multicenter Investigators Group. Circulation. 1994:90(3):1279-86. 